\title{
Antibody targeting of CD24 efficiently retards growth and influences cytokine milieu in experimental carcinomas
}

\author{
A V Salnikov ${ }^{1,2}$, N P Bretz ${ }^{1}$, C Perne ${ }^{1}$, J Hazin ${ }^{1}$, S Keller $^{1}$, M Fogel ${ }^{3}$, I Herr ${ }^{2}$, T Schlange ${ }^{4}$, \\ G Moldenhauer ${ }^{1}$ and $P$ Altevogt ${ }^{\star}, 1$ \\ ${ }^{1}$ Department of Translational Immunology, German Cancer Research Center and National Center for Tumor Diseases, \\ Heidelberg, Germany; ${ }^{2}$ Molecular OncoSurgery Group, Department of General Surgery, University of Heidelberg and German \\ Cancer Research Center, Heidelberg, Germany; ${ }^{3}$ Kaplan Medical Center, Rehovot, Israel and ${ }^{4}$ Bayer Schering Pharma AG, \\ Wuppertal, Germany
}

Background: The targeting of cancer stem cells by monoclonal antibodies offers new options for therapy. CD24 is a glycosylphosphatidylinositol-anchored membrane protein with a small protein core and a high level of glycosylation. It is overexpressed in many human carcinomas and is correlated with poor prognosis. CD24 is a marker for pancreatic and ovarian cancer stem cells, whereas breast cancer stem cells are negative for CD24. In cancer cell lines, changes of CD24 expression can alter cellular properties in vitro and tumour growth in vivo. We have shown before that monotherapy with monoclonal antibody (mAb) SWA11 to CD24 effectively retarded tumour growth in xenotransplanted mice.

Methods: Here, we have investigated in more detail the molecular mechanisms of mAb SWA11 therapeutic effects in A549 lung and SKOV3ip ovarian carcinoma models in scid/beige and CD1 mice, respectively. We focused on anti-proliferative, pro-apoptotic, anti-angiogenic and microenvironmental effects of SWA11 mAb treatment.

Results: We find that CD24 targeting is associated with changes in tumour cell proliferation and angiogenesis. The treatment lead to increased infiltration of tumour tissues with immune cells suggesting involvement of ADCC. We found that SWA11 mAb treatment strongly altered the intratumoural cytokine microenvironment. The addition of SWA11 mAb to gemcitabine treatment strongly potentiated its anti-cancer efficacy in A549 lung cancer model.

Conclusion: Our data demonstrate that targeting of CD24 could be beneficial for the anti-cancer treatment combined with standard chemotherapy regimes.

Monoclonal antibodies have emerged as a new and important pillar for cancer therapy (Galluzzi et al, 2012). During the past two decades molecular biology has provided means to create chimeric, humanised or fully human antibodies for the treatment of major malignant diseases (Presta, 2008). To date, 11 antibodies and antibody-conjugates are approved as cancer therapeutics for marketing in Europe and the United States (Reichert, 2012). They comprise unmodified antibodies, antibody-drug conjugates as well as conjugates with radionuclides and a bispecific antibody
(Reichert, 2011). These new reagents are able to interact with human effector molecules and thereby synergize with or even substitute for conventional chemotherapeutic regimens (Scott et al, 2012; Shuptrine et al, 2012; Vanneman and Dranoff, 2012). One might envision that the discovery of novel target molecules will broaden the applicability of antibody-based therapy towards additional malignancies and, most importantly, against cancer stem cells.

CD24 is a highly glycosylated protein that is linked to the membrane via glycosylphosphatidylinositol (GPI)-anchor and is 
exclusively localised in membrane lipid raft domains (Kay et al, 1991; Schabath et al, 2006). In humans, CD24 has a protein core of only 31 amino acids with 16 potential O- and N-glycosylation sites. (Kay et al, 1991). It is expressed predominantly on cells of the hematopoietic lineage such as B lymphocytes, monocytes, granulocytes and activated $\mathrm{T}$ lymphocytes (for review see (Fang et al, 2010)). CD24 is also overexpressed in many human cancers and its expression is associated with poor prognosis (Kristiansen et al, 2004, 2010). Importantly, CD24 was identified as a marker for cancer stem cells for a variety of cancer types (Woodward and Sulman, 2008). In tumour cells, CD24 was identified as a ligand of P-selectin that supports the rolling of breast carcinoma cells on endothelial cells and adhesion to platelets (Aigner et al, 1997, 1998; Friederichs et al, 2000; Baumann et al, 2005), and might therefore facilitate the metastatic spread of tumour cells (Kristiansen et al, 2004; Baumann et al, 2005). CD24 expression has also been shown to regulate tumour cell proliferation, migration and invasion (Senner et al, 1999; Baumann et al, 2005; Schabath et al, 2006; Smith et al, 2006; Fukushima et al, 2007; Runz et al, 2008; Sagiv et al, 2008; Ahmed et al, 2009; Wang et al, 2010; Mierke et al, 2011; Bretz et al, 2012) and was found to affect gene expression in colon and pancreatic cell lines (Sagiv et al, 2008). Monoclonal antibody to CD24 were therapeutically very efficient and inhibited the growth of the xenograft in therapy models of human cancer (Bretz et al, 2011; Baumann et al, 2012; Bretz et al, 2012), although the molecular mechanism of these effects remained somewhat elusive.

We recently reported that the binding of the CD24 specific monoclonal antibody (mAb) SWA11 to tumour cells in situ was accompanied by changes in Src phosphorylation and the expression of STAT3-dependent genes (Bretz et al, 2011; Baumann et al, 2012; Bretz et al, 2012). It was found that CD24 alters the phosphorylation of FAK and STAT3 via the lipid raft component Src and thereby affects gene expression, tumour cell adhesion and invasion (Bretz et al, 2011; Baumann et al, 2012; Bretz et al, 2012). In addition, beside these direct effects due to target antigen binding, mAbs can trigger important immunological effector mechanisms such as ADCC or complement activation that may contribute to the overall therapeutic efficacy. In the present study, we therefore investigated the molecular mechanisms of anti-CD24 $\mathrm{mAb}$ therapy in more detail. We demonstrate that CD24 mAb affected cell proliferation but not apoptosis and also altered the cytokine milieu within the tumour microenvironment of treated mice. Our preclinical results suggest that CD24 is a promising novel target for antibody-mediated cancer therapy that is worth investigating in early clinical trials.

\section{MATERIALS AND METHODS}

Cell lines. Human lung adenocarcinoma cell line A549 and ovarian carcinoma cell line SKOV3ip were obtained from the American Type Culture Collection (Manassas, VA, USA). The cell lines were authenticated by the German Resource Center for Biological Material (Braunschweig, Germany) and throughout the culture by assessment of typical morphology by the investigators. Mycoplasma-negative cultures were ensured by weekly tests. Cells were cultured in RPMI-1640 or DMEM medium (Sigma-Aldrich, Deisenhoffen, Germany) supplemented with $10 \%$ heat-inactivated fetal calf serum (Biochrom, Berlin, Germany), $2 \mathrm{~mm}$ L-glutamine (Invitrogen, Karlsruhe, Germany) and $1 \mathrm{~mm}$ sodium pyruvate (Invitrogen). All cells were maintained in a humidified atmosphere at $37^{\circ} \mathrm{C}$ and $5 \% \mathrm{CO}_{2}$.

Monoclonal antibodies. The mAb SWA11 against the LAP epitope of the protein core of human CD24 was described before (Jackson et al, 1992; Schabath et al, 2006). The mAb L1-9.3/2a against human L1CAM has been described before (Wolterink et al, 2010).
Both mAbs are of the IgG2a isotype. Isotype control C1.18 mAb was obtained from Bio X Cell (West Lebanon, NH, USA).

In vivo xenograft tumour models. A549 human lung cancer model: 4 - to 5-week-old female SCID beige mice were purchased from Charles River Laboratories (Wetzlar, Germany) and housed at the animal facility of the German Cancer Research Center (Heidelberg, Germany). A549 human lung carcinoma cells $(5 \times$ $10^{6}$ in $100 \mu \mathrm{l}$ of PBS) were transplanted subcutaneously into the right flank of the mice. Fourteen days later, when A549 tumours reached a volume of $50-90 \mathrm{~mm}^{3}$ the SWA11 mAb treatment was initiated. Tumour size was measured externally using a caliper. Tumour volume was calculated according to the formula: $V=4$ $\pi^{*} a^{*} b^{*} c / 3$, where $a, b$ and $c$ are semi-diameters in three dimensions. Data are presented as a relative tumour volume increase from the time of antibody administration. Animals were killed on day 37 after tumour cell implantation. Tumours were dissected, weighed, embedded in OCT, snap frozen and stored at $-80{ }^{\circ} \mathrm{C}$ for further analysis. Two independent in vivo SWA11 treatment experiments with A549 human lung cancer model were performed and data from one representative experiment are shown. In one of these experiments, combined treatment with gemcitabine was investigated.

SKOV3ip human ovarian cancer model: this model was described in detail elsewhere (Wolterink et al, 2010). Briefly, pathogen-free, female athymic CD1 nu/nu mice (Charles River Laboratories) were inoculated with $5 \times 10^{6}$ human SKOV3ip ovarian cancer cells transfected with the luciferase plasmid pcDNA3.1 into the peritoneal cavity. Four days later, tumourbearing animals were randomized and mice received either two injections of SWA11 mAb per week for 4 weeks $\left(10 \mathrm{mg} \mathrm{kg}^{-1}\right.$ of mouse body weight), L1-9.3 or unspecific $\operatorname{IgG}_{2 \mathrm{~A}}$ or PBS vehicle. At the endpoint, mice were killed, weighed and the peritoneal cavity was thoroughly examined for the formed tumour nodules. SKOV3ip tumours were excised, weighed and stored at $-80^{\circ} \mathrm{C}$ for further analysis. Two independent in vivo SWA11 mAb treatment experiments with SKOV3ip ovarian cancer model were performed and data from one representative experiment are shown.

Combined SWA11 $\mathrm{mAb}$ and gemcitabine treatment: Animals bearing established A549 tumours first received an injection of SWA11 mAb $\left(10 \mathrm{mg} \mathrm{kg}^{-1}\right)$ followed by administration of gemcitabine at a dose of $12 \mathrm{mg} \mathrm{kg}^{-1}$ (10\% of maximum tolerated dose for SCID mice) 1 day later. Treatment was repeated three times with a 5-day interval. Animal experiments were approved by the Baden-Württemberg animal oversight committee (Regierungspräsidium Karlsruhe, Germany).

Immunohistochemistry and immunofluorescence. Immunohistochemistry was performed on $6 \mu \mathrm{m}$ frozen xenograft tumour tissue sections using the standard avidin-biotin technique with a Vectastain avidin: biotinylated enzyme complex (ABC) Elite kit (Vector Laboratories, Burlingame, CA, USA) or a ZytoChem Plus horseradish peroxidase (HRP) polymer system kit (Zytomed Systems, Berlin, Germany). Briefly, tissue samples were fixed in acetone (Merck, Darmstadt, Germany) or $4 \%$ paraformaldehyde (Merck) followed by incubation with $20 \%$ normal goat or rabbit serum in PBS to block unspecific binding of antibodies. After incubation with primary $\mathrm{mAb}$ and washing with PBS three times, tissue samples were incubated with biotinylated secondary antibody or with a HRP mouse/rabbit polymer system. Diaminobenzidin (DAB) (Invitrogen) or 3-amino-9-ethylcarbazole (Zytomed Systems) were used as chromogens. The following primary antibodies were used: rat anti-mouse CD31 mAb (1:100 dilution) (BD Pharmingen, Heidelberg, Germany) for detection of endothelial cells, rabbit antiNG2 chondroitin sulphate proteoglycan Ab (1:50 dilution) (EMD Millipore, Temecula, CA, USA) to detect activated pericytes, mouse anti- $\alpha$-smooth muscle actin FITC-conjugated $\mathrm{mAb}$ (1:50 dilution) (1A4, Sigma-Aldrich) for detection of vascular smooth muscle cells 
and pericytes, rabbit anti-human Ki-67 mAb (1:400 dilution) (Epitomics Inc., Burlingame, CA, USA) as a marker of tumour cell proliferation. Biotinylated goat anti-mouse IgG, biotinylated goat anti-rabbit and biotinylated rabbit anti-rat $\operatorname{IgG}(1: 200$ dilution) (Vector Laboratories) were used as secondary antibodies. For double immunofluorescence staining, goat anti-rabbit IgG conjugated to Alexa-488 or goat anti-rat Alexa $594 \operatorname{IgG}$ (1:400 dilution) (Invitrogen) were used as secondary antibodies. Omission of primary antibody was used as a negative control. Apoptosis was detected by staining for active caspase 3 with rabbit anti-human polyclonal antibody ( $1: 100$ dilution) (R\&D Systems, Abingdon, UK). Tissue stainings were examined at $\times 400$ and $\times 100$ magnification with a Leica DMRB microscope (NIH, Bethesda, Maryland, USA). Images were captured with a SPOT Flex digital colour camera (Diagnostic Instruments Inc., Sterling Heights, MI, USA) and analysed with SPOT Advanced version 4.6 software. Ki-67-positive and active caspase 3 -positive cells were counted at $\times 400$ magnification in 10 random fields of vision $\left(0.089 \mathrm{~mm}^{2}\right)$ per slide ( $n=3-4$ mice per group, unless otherwise specified). Data in each treatment group are presented as the mean percentage of Ki-67positive or active caspase 3-positive cells per total tumour cellular mass counted in the same fields of vision. CD31-positive blood vessels were counted at $\times 100$ magnification in 10 random fields of vision $\left(1.46 \mathrm{~mm}^{2}\right)$ per slide $(n=3-4$ mice per group, unless otherwise specified). Data in each treatment group are presented as the mean number of CD31-positive blood vessels per $\mathrm{mm}^{2}$ of tumour tissue. The number of CD31-positive blood vessels, proliferating and apoptotic tumour cells was counted by an investigator who was blinded to the type of treatment received by the mice.

TUNEL assay. To quantify the number of apoptotic cells, $6 \mu \mathrm{m}$ cryosections of xenograft tumours were subjected to a TUNEL assay with TACS TdT in situ apoptosis detection kit (R\&D Systems) according to the manufacturer's recommendations and modified by signal enhancement using a Vectastain ABC Elite kit (Vector Laboratories) and colour development using a DAB kit (Invitrogen). TUNEL-positive cells were counted at $\times 400$ magnification in 10 random fields of vision $\left(0.089 \mathrm{~mm}^{2}\right)$ per slide ( $n=3-4$ mice per group, unless otherwise specified). Data in each treatment group are presented as the mean percentage of TUNELpositive cells per total tumour cellular mass counted in the same fields of vision.

ELISA. Levels of mouse RANTES/CCL5, MCP-1/CCL2 and MIG/ CXCL9 in xenograft tumours were analysed using respective ELISA kits (R\&D Systems) according to the manufacturer's recommendations. Proteins were extracted from tumours using the following lysis buffer: $250 \mathrm{~mm} \mathrm{NaCl}, 50 \mathrm{~mm}$ HEPES, $0.5 \%$ NP-40, $10 \%$ glycerol, $2 \mathrm{~mm}$ EDTA, $10 \mathrm{~mm} \mathrm{NaF}, 1 \mathrm{~mm}$ Na-orthovanadate, $1 \mathrm{~mm}$ PMSF, $10 \mathrm{mg} \mathrm{ml}^{-1}$ of each leupeptin and aprotinin. Tumour tissue samples were homogenised in the lysis buffer using a FastPrep-24 homogeniser (MP Biomedicals, Eschwege, Germany).

Cytokine protein array. Relative levels of 40 different cytokines and chemokines in xenograft tumour lysates were evaluated using a mouse cytokine antibody array kit (Proteome Profiler, R\&D Systems) according to the manufacturer's recommendations. Pixel density in each spot of the array was quantified using ImageJ 1.44o software (http://rsb.info.nih.gov/ij/features.html). Cytokines detectable by the antibody array kit included: BLC/CXCL13/ BCA-1, C5a, G-CSF, GM-CSF, I-309/CCL1/TCA-3, Eotaxin/ CCL11, sICAM-1/CD54, IFN- $\gamma$, IL-1 $\alpha$, IL-1 $\beta$, IL-1Ra, IL-2, IL-3, IL-4, IL-5, IL-6, IL-7, IL-10, IL-13, IL-12 p70, IL-16, IL-17, IL-23, IL-27, IP-10/CXCL10/CRG-2, I-TAC/CXCL11, KC, M-CSF, JE/CCL2/MCP-1, MCP-5/CCL12, MIG/CXCL9, MIP-1 $\alpha / C C L 3$, MIP-1 $\beta / C C L 4$, MIP-2, RANTES/CCL5, SDF-1/ CXCL12, TARC/CCL17, TIMP-1, TNF- $\alpha$, TREM-1.
Angiogenesis protein array. Relative levels of 55 human and 53 mouse angiogenesis-related proteins in xenograft tumour lysates were evaluated using human or mouse angiogenesis array kits (Proteome Profiler, R\&D Systems) according to the manufacturer's recommendations. Pixel density in each spot of the array was quantified using ImageJ 1.440 software. Proteins detectable by the human angiogenesis array kit included: activin A, ADAMTS-1, angiogenin, angiopoietin-1, angiopoietin-2, angiostatin/plasminogen, amphiregulin, artemin, coagulation factor III/TF, CXCL16, DPPIV/CD26, EGF, EG-VEGF/PK1, endoglin/CD105, endostatin/collagen XVIII, endothelin-1, FGFa/FGF1, FGFb/FGF-2, FGF-4, FGF-7/KGF, GDNF, GM-CSF, HB-EGF, HGF, IGFBP-1, IGFBP-2, IGFBP-3, IL- $1 \beta$, IL-8/CXCL8, TGF- $\beta$, Leptin, MCP-1/CCL2, MIP-1 $\alpha /$ CCL3, MMP-8, MMP-9, NRG1- $\beta 1$, pentraxin-3/TSG-14, PD-ECGF, PDGF-AA, PDGF-AB/PDGF-BB, persephin, platelet factor 4/CXCL4, PlGF, prolactin, serpin B5, serpin E1, serpin F1, TIMP-1, TIMP-4, trombospondin-1, trombospondin-2, uPA, vasohibin, VEGF, VEGF-C.

Proteins detectable by the mouse angiogenesis array kit included: ADAMTS-1, amphiregulin, angiogenin, angiopoietin-1, angiopoietin-3, coagulation factor III/TF, CXCL16, Cyr61/CCN1, IGFBP-10, Dll4, DPPIV/CD26, EGF, endoglin/CD105, endostatin/collagen XVIII, endothelin-1, FGFa/FGF-1, FGFb/FGF-2, FGF-7, fractalkine/CX3CL1, GM-CSF, HB-EGF, HGF, IGFBP-1, IGFBP-2, IGFBP-3, IL- $1 \alpha$, IL-1 $\beta$, IL-10, IP-10/CXCL10, KC/CXCL1/GRO $\alpha$, leptin, MCP-1/CCL2, MIP-1 $\alpha /$ CCL3, MMP-3, MMP-8 (pro form), MMP-9 (pro and active form), NOV/CCN3/IGFBP-9, osteopontin, PD-ECGF, PDGF-AA, PDGF-AB/PDGF-BB, pentraxin-3, platelet factor 4/CXCL4, PlGF, prolactin, proliferin, SDF-1, serpin E1, serpin F1, trombospondin-2, TIMP-1, TIMP-4, VEGF and VEGF-B.

Net antibody uptake assay. Equal amounts of mAbs (L1-9.3 and SWA11) were conjugated with Alexa-488 (Invitrogen). The degree of coupling was calculated to ensure similar labelling efficacy. SKOV3ip cells were detached with trypsin/EDTA, resuspended in culture medium, counted and divided into aliquots of equal cell number. Cells were incubated at $37^{\circ} \mathrm{C}$ for different time points in the continuous presence of the labelled antibody $\left(10 \mu \mathrm{g} \mathrm{ml}^{-1}\right)$. At each time point, cells were sedimented at $800 \mathrm{~g}$, washed once with ice-cold PBS and fixed with 4\% PFA for $20 \mathrm{~min}$ on ice. For each time point duplicates were prepared. Fixed cells were washed twice with PBS and incubated with an anti-Alexa-488 antibody $\left(25 \mu \mathrm{g} \mathrm{ml}^{-1}\right.$ ) (Invitrogen) for $30 \mathrm{~min}$ to achieve the quenching of cell surface fluorescence. To assess quenching efficacy and total surface intensity, cells were labelled on ice for $30 \mathrm{~min}$ and either quenched or left unquenched. Internalised fluorescence at different time points was set in relation to total surface intensity. All samples were measured on a FACS Canto II (BD Biosciences, Heidelberg, Germany) and analysed using FlowJo Software (TreeStar Inc., Ashland, OR, USA).

Cytofluorographic and western blot analysis. Fluorescent staining of cells, FACS analysis and western blot analysis of tumour cell lysates were described in detail before (Wolterink et al, 2010; Bretz et al, 2011).

Statistical analysis. Data are presented as the mean \pm s.d. Student's $t$-test was used to evaluate the difference between groups. $P<0.05$ was considered statistically significant.

\section{RESULTS}

Effects of monotherapy with SWA11 mAb on tumour growth and cell proliferation in experimental carcinomas. Previously, we have shown that monotherapy with anti-CD24 SWA11 antibody retarded the growth and interfered with Src signalling in cancer cells growing as xenografts on immuno-comprimized 

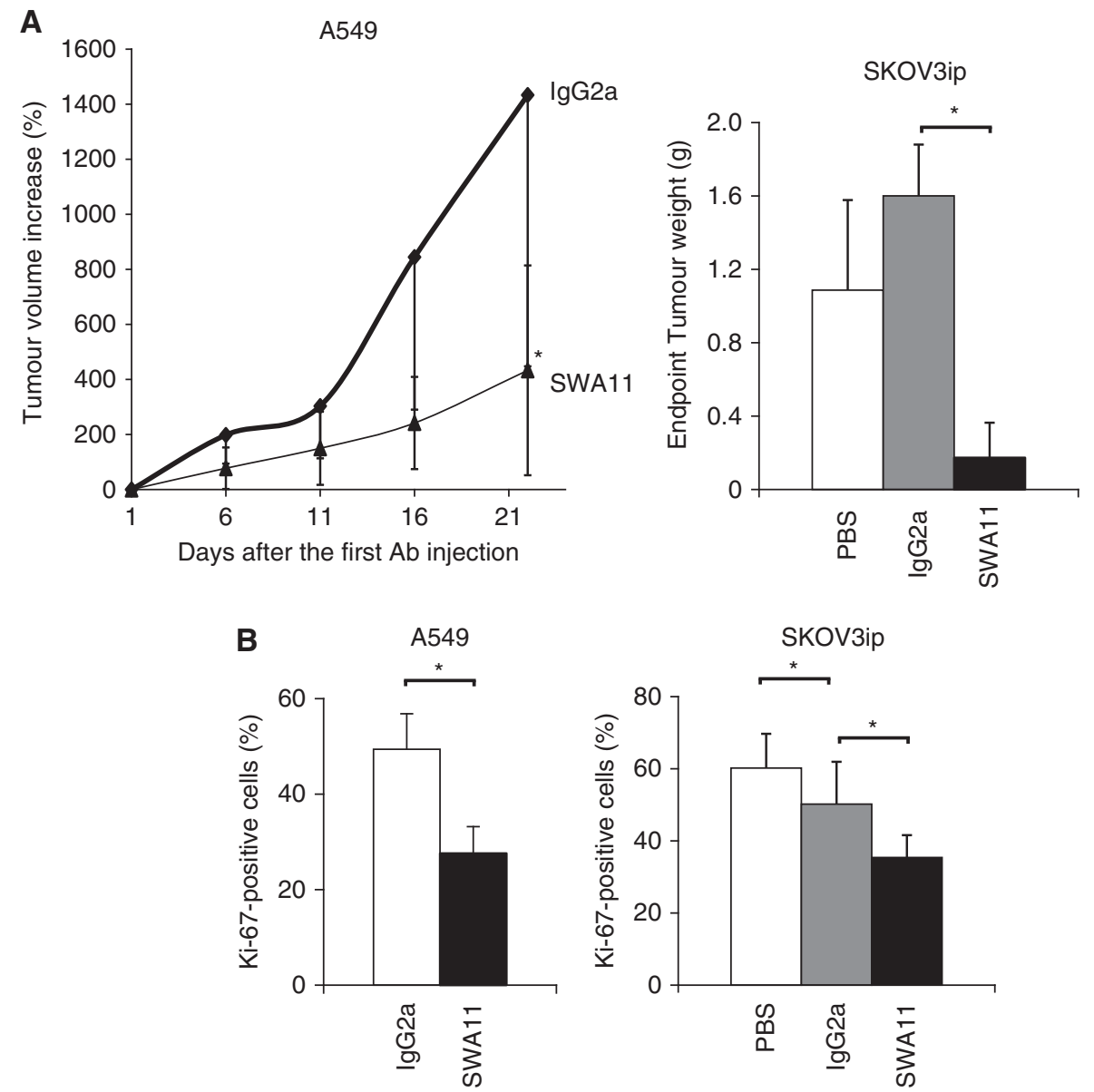

Figure 1. Anti-tumour efficiency of SWA11 mAb treatment in vivo. (A) SCID beige mice with established xenograft A549 lung carcinomas ( $n=5$ per group) or CD1 mice inoculated with SKOV3ip ovarian carcinoma cells ( $n=10$ per group) received treatment with SWA11 mAb (10 mg kg $\left.{ }^{-1}\right)$. In A549 tumour model, SWA11 mAb or $\operatorname{lgG}_{2 A}\left(10 \mathrm{mg} \mathrm{kg}^{-1}\right)$ were administered four times with a 5-day interval. In SKOV3ip model mice received eight doses of SWA11 mAb $\left(10 \mathrm{mg} \mathrm{kg}^{-1}\right), \mathrm{IgG}_{2 \mathrm{~A}}\left(10 \mathrm{mg} \mathrm{kg}^{-1}\right)$ or PBS twice weekly. External size of A549 tumours was measured with a caliper. $\star P<0.05$. (B) Tumour cell proliferation was evaluated by immunohistochemistry on frozen tumour sections. The percentage of Ki-67-positive cells per total tumour cellular mass was determined in 4-5 tumours per group. ${ }^{\star} P<0.05$.

mice (Bretz et al, 2012). To investigate the anti-cancer effects of SWA11 mAb in more detail, xenograft tumours were analysed for cellular proliferation and apoptosis. Consistent with our previous results, SWA11 mAb treatment strongly inhibited growth of A549 lung and SKOV3ip ovarian carcinoma xenografts (Figure 1A). SWA11 mAb treatment decreased the percentage of proliferating Ki-67-positive tumour cells in A549 and SKOV3ip tumours compared with $\operatorname{IgG}_{2 \mathrm{~A}}$-treated controls (Figure 1B). Surprisingly, SWA11 mAb therapy had only a minor effect on tumour cell apoptosis. The percentage of apoptotic, active caspase 3-positive cells or TUNEL-positive cells did not differ between SWA11treated and $\mathrm{IgG}_{2 \mathrm{~A}}$-treated control groups (data not shown).

SWA11 mAb treatment increased infiltration of tumour tissues by macrophages. To get further insight into the effector mechanisms of SWA11 mAb treatment, we analysed tumours for inflammatory cell infiltration. We observed an increased infiltration of SKOV3ip tumours by F4/80-positive macrophages (Figure 2). Unfortunately, it was not possible/feasible to quantify the number of F4/80-positive macrophages due to a very diffuse pattern of the immunostaining. Therefore, we show one representative IHC picture from all analysed tumours $(n=10$ per group) (Figure 2). In addition, there was a tendency to the increased macrophage infiltration of A549 tumours after SWA11 $\mathrm{mAb}$ treatment ( $n=5$ per group) (data not shown). Similar diffuse pattern was observed in IHC for CD68 as an additional marker for macrophages.

There were no differences in the granulocyte infiltration of SKOV3ip and A549 tumours between SWA11 mAb-treated and $\mathrm{IgG}_{2 \mathrm{~A}}$-treated control groups (data not shown). Granulocyte infiltration assessed by Gr-1 staining was very heterogeneous with foci of high infiltration as well as of regions with very low granulocyte density, which made the assessment of the average density of granulocytes not possible.

SWA11 mAb treatment affected cytokine milieu in xenograft tumours. To address the question whether SWA11 mAb treatment influenced the tumour microenvironment, we analysed the cytokine profile in the tumours using protein arrays. To get an indication on the changes in the cytokine microenvironment, lysates obtained from a single experiment of the two independently performed for each tumour model were tested in cytokine array and further validated by ELISAs. In A549 lung carcinomas grown in SCID beige mice, an increased expression of multiple cytokines was observed after SWA11 mAb therapy. In particular, the levels of CCL1, CCL2/MCP-1, CCL12, CXCL9/MIG, CXCL10, CXCL11, IFN- $\gamma$, IL- $1 \alpha$, IL- $1 \beta$, IL-1Ra were upregulated in SWA11 mAbtreated tumours compared with $\operatorname{IgG}_{2 \mathrm{~A}}$ controls (Figure $3 \mathrm{~A}$ ). We confirmed the increased protein levels of three selected cytokines CCL5/RANTES, CXCL9/MIG and CCL2/MCP-1 by ELISA 


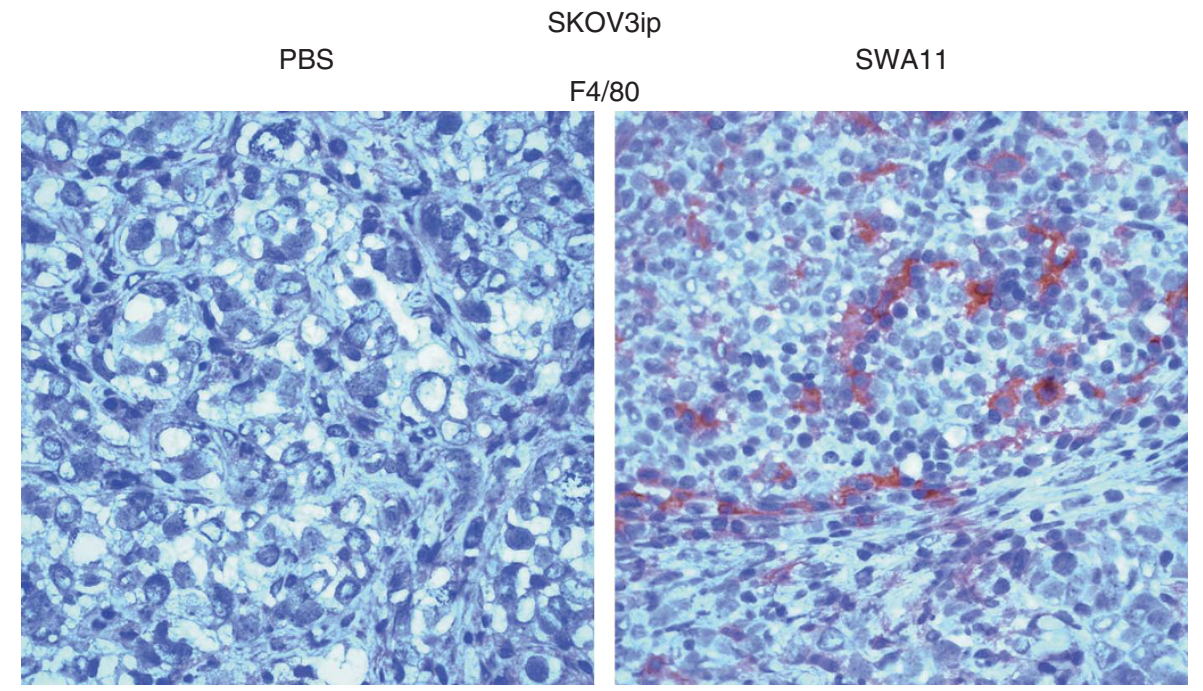

Figure 2. Macrophage infiltration of tumour tissues after SWA11 mAb treatment. Macrophages in tumour tissues were detected by immunohistochemistry using F4/80 antibody. Images were taken under $\times 400$ magnification. Images from one tumour per group $(n=5)$ are shown.

A

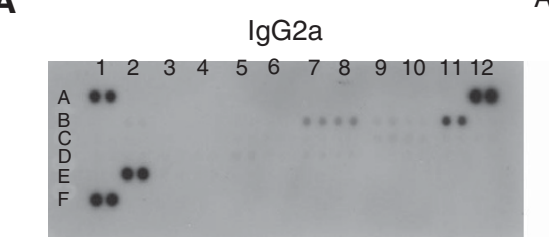

A549

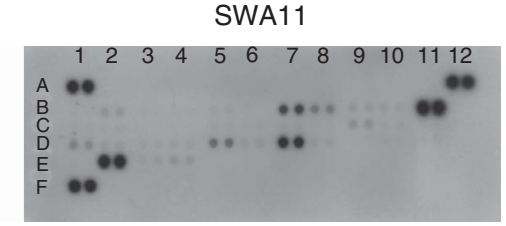

$\lg 2 \mathrm{a}$

- SWA11
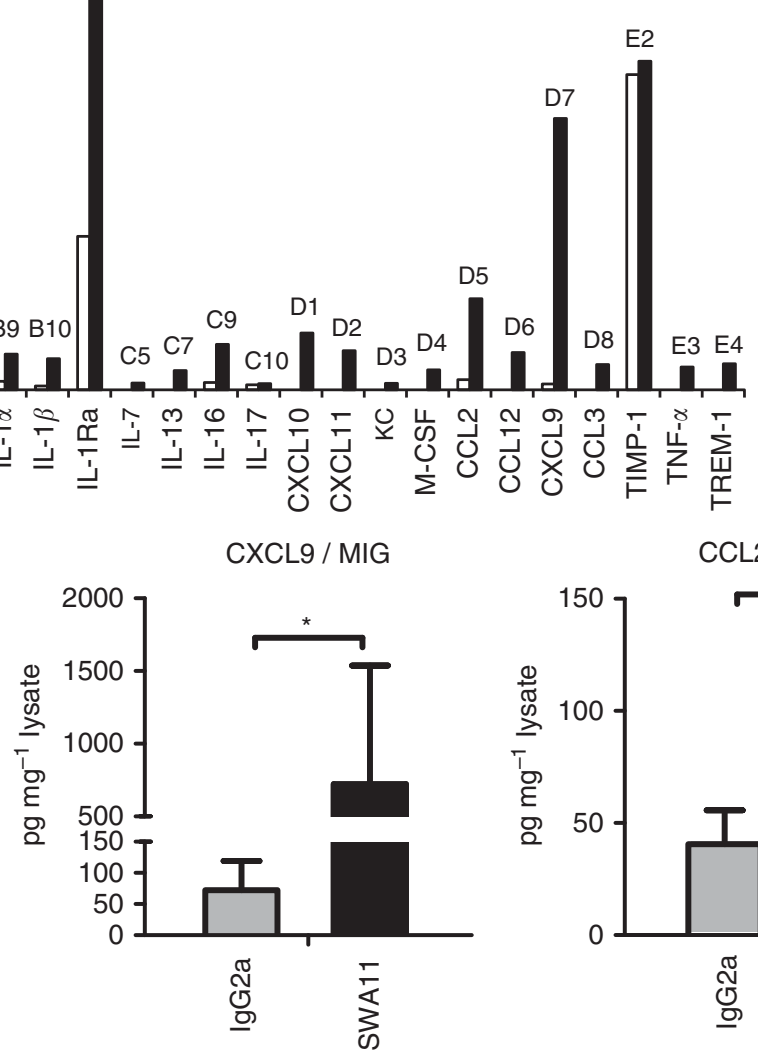
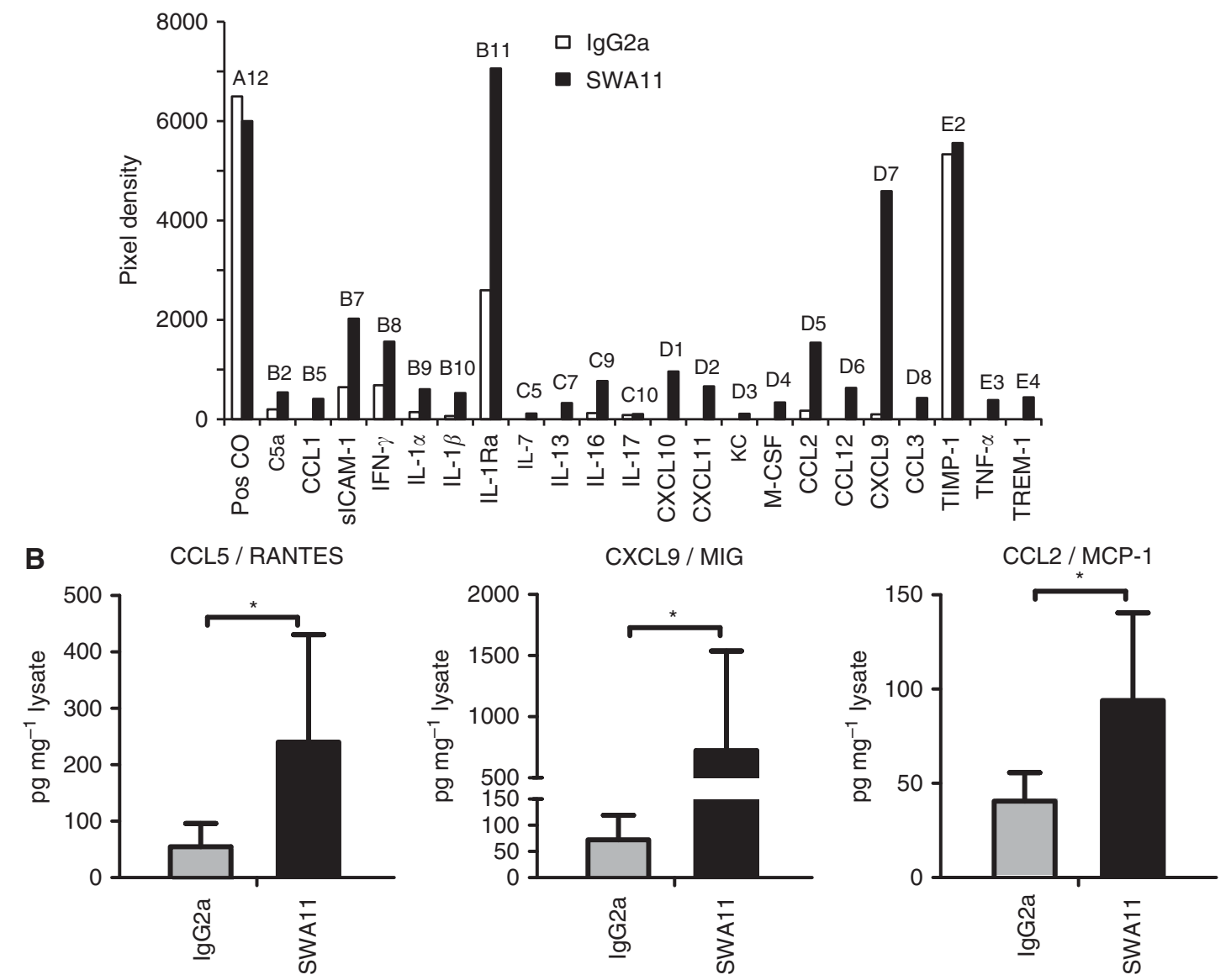

Figure 3. Effects of SWA11 mAb treatment on intratumoural cytokine milieu in A549 tumours. (A) The levels of 40 different cytokines were determined in tumour lysates using a cytokine protein arrays. The level of cytokines was quantified using ImageJ software. Representative arrays from two independent SWA11 mAb treatment experiments are shown. (B) Protein levels of CCL5/RANTES, CXCL9/MIG and CCL2/MCP-1 in tumour lysates ( $n=5$ per group) were determined by ELISA. Data are normalised to the total protein concentration in tumour lysates. ${ }^{\star} P<0.05$. 
A SKOV3ip
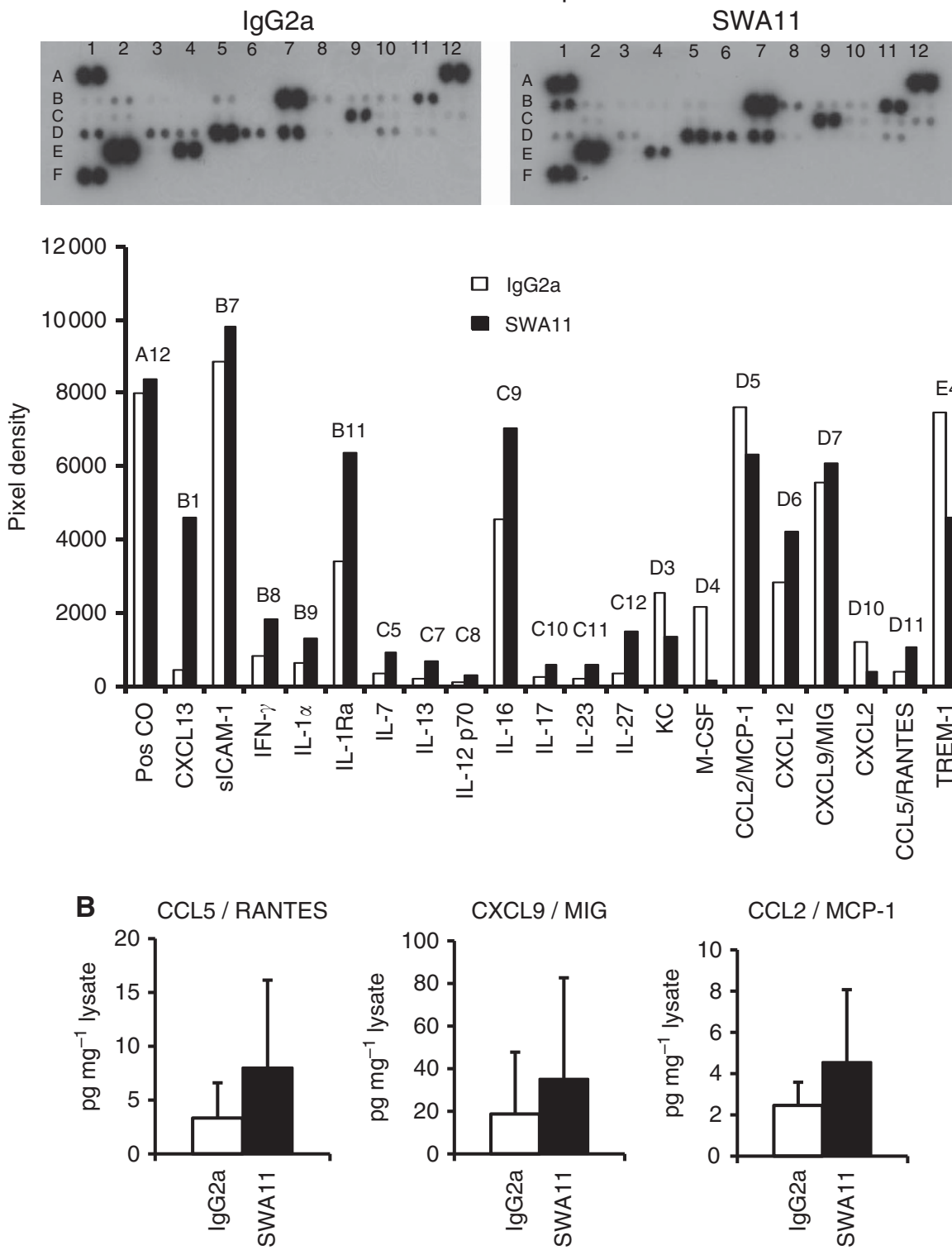

Figure 4. Effects of SWA11 mAb treatment on intratumoural cytokine milieu in SKOV3ip tumours. (A) The levels of 40 different cytokines were determined in tumour lysates using cytokine protein arrays. The level of cytokines was quantified using ImageJ software. Representative arrays from two independent SWA11 mAb treatment experiments are shown. (B) Protein levels of CCL5/RANTES, CXCL9/MIG and CCL2/MCP-1 in tumour lysates ( $n=5-6$ per group) were determined by ELISA. Data are normalised to the total protein concentration in tumour lysates.

(Figure 3B). Comparable effects of SWA11 mAb on the cytokine profile were observed in the SKOV3ip model in CD1 mice (Figure 4A). There was an increase in the levels of several cytokines, including CCL13, CXCL12, CXCL9, CCL5/RANTES, IFN- $\gamma$, IL- $1 \alpha$ and IL-1Ra. ELISA analysis showed a tendency to the increased protein levels of CCL5/RANTES, CXCL9/MIG and CCL2/MCP-1 after SWA11 mAb treatment (Figure 4B). These results suggest that $\mathrm{SWA1} 1 \mathrm{mAb}$ treatment induced severe changes in the tumour microenvironment that may have contributed to the therapeutic effect.

SWA11 treatment exhibited anti-angiogenic effects in xenograft tumours. Analysis of blood vessel density in A549 and SKOV3ip tumours revealed reduced numbers of CD31-positive blood vessels after SWA11 mAb treatment compared with $\mathrm{IgG}_{2 \mathrm{~A}}$ or PBS vehicle controls (Figure 5A). To investigate whether the anti-angiogenic effects of the SWA11 mAb were due to the changes in the tumour microenvironment, we evaluated levels of pro- and anti-angiogenic cytokines and growth factors in tumour lysates obtained from a single experiment of the two independently performed for each tumour model. Surprisingly, the levels of both human and mouse proangiogenic factors, that is, VEGF, FGFb, PlGF-2 and some others, were upregulated after SWA11 mAb treatment (Figure 5B and data not shown). In contrast, only mouse TSP-2 was slightly upregulated among anti-angiogenic factors (Figure 5B). We excluded the possibility that a reduced blood vessel density after SWA11 mAb treatment was due to the vascular maturation or normalisation. Thus, analysis of pericyte coverage of blood vessels in A549 tumour xenografts showed that the majority of CD31-positive vessels were covered by NG2-positive activated pericytes as well as by $\alpha$-smooth muscle actin-positive cells (Supplementary Figure 1).

Antibody targeting of CD24 potentiates efficacy of chemotherapy in experimental carcinomas in vivo. Next, we investigated whether antibody targeting of CD24 increases the antitumour efficacy of chemotherapy. We tested whether pretreatment 

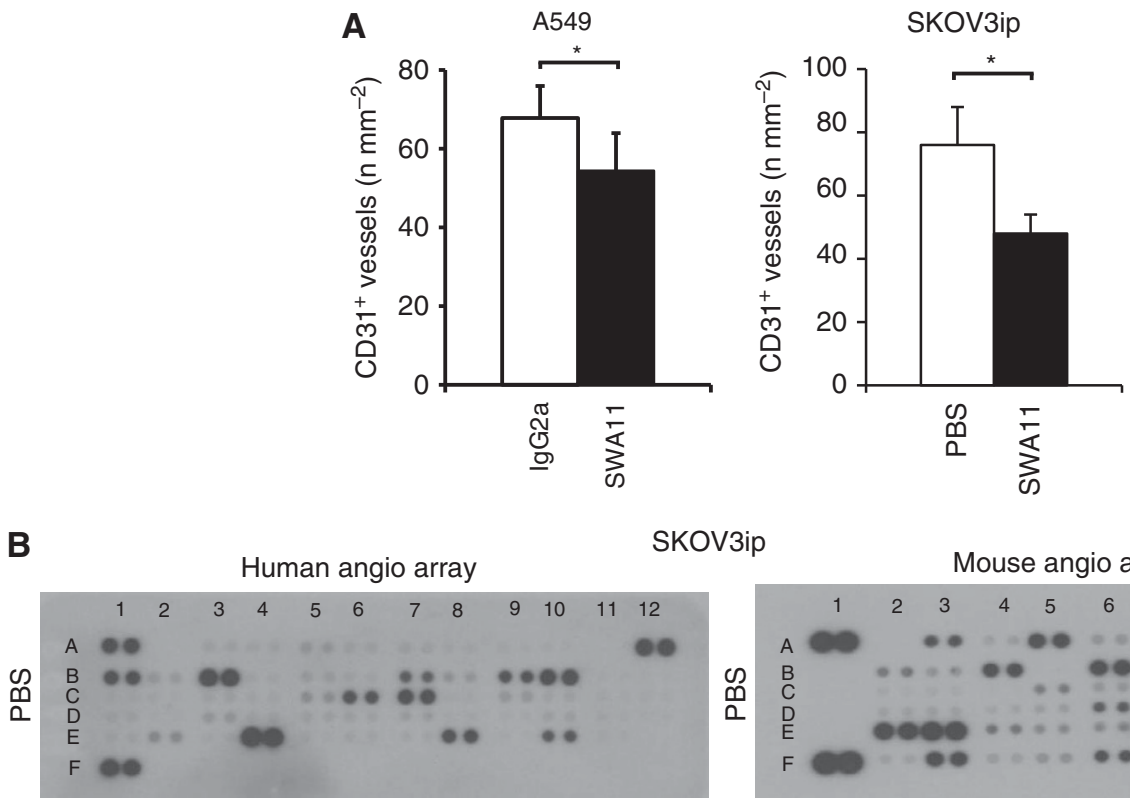

Mov3ip angio array
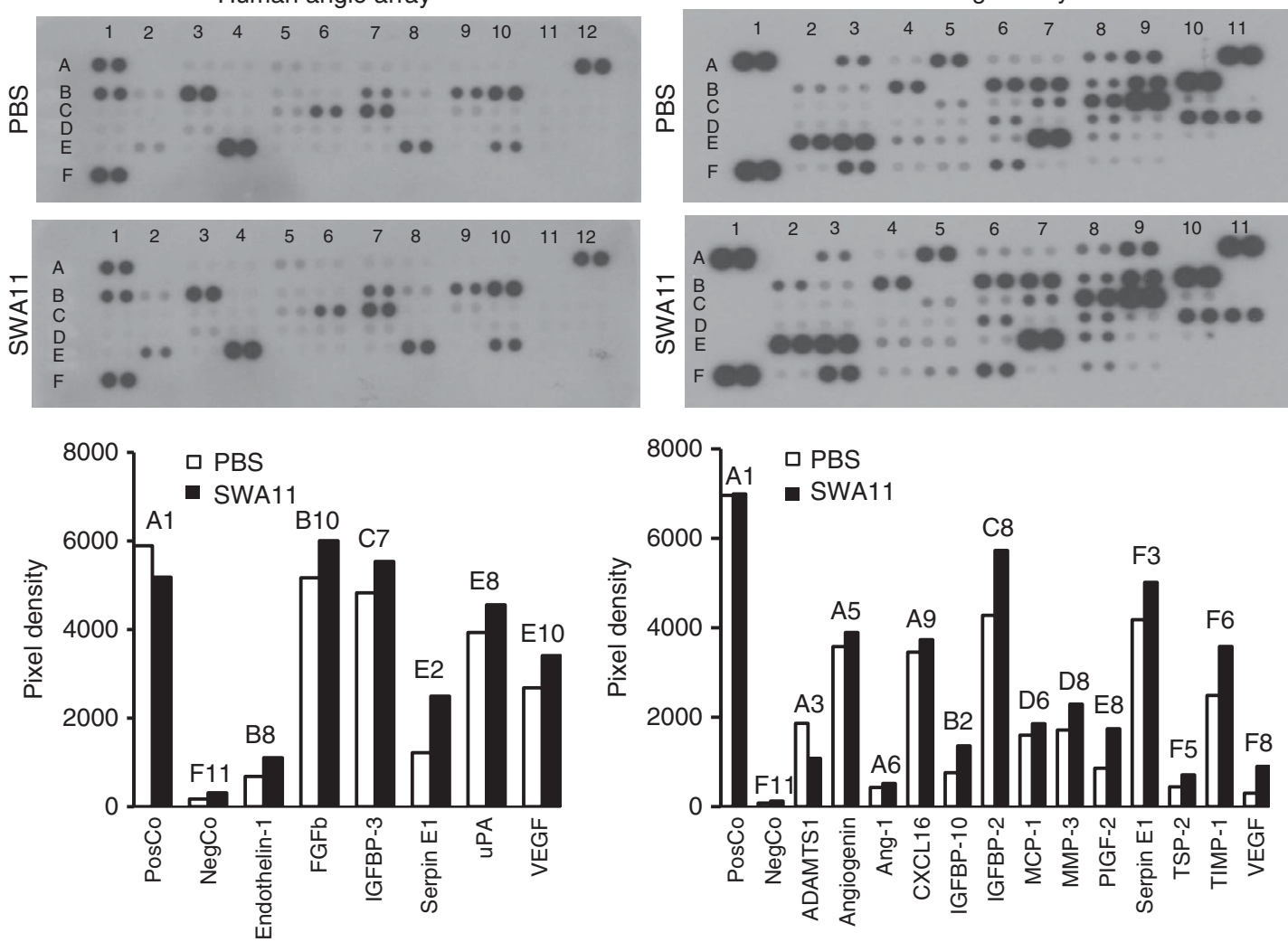

Figure 5. Effects of SWA11 mAb treatment on angiogenesis and expression of pro- and anti-angiogenic factors in xenograft tumours. (A) The density of blood vessels in A549 and SKOV3ip tumours was analysed by immunohistochemistry using CD31 as a marker of endothelial cells. CD31positive blood vessels were counted in 10 random fields of vision under $\times 100$ magnification. Data in each treatment group are presented as the mean number of CD31-positive blood vessels per $\mathrm{mm}^{2}$ of tumour tissue. ${ }^{\star} P<0.05$. (B) Levels of mouse and human pro- and anti-angiogenic factors were analysed in tumour lysates using protein arrays and quantified by Image J software.

with SWA11 mAb would potentiate the effects of gemcitabine. In A549 tumour model, mice with established xenograft tumours first received an injection of SWA11 $\mathrm{mAb}\left(10 \mathrm{mg} \mathrm{kg}^{-1}\right)$ followed by administration of gemcitabine at a dose of $12 \mathrm{mg} \mathrm{kg}^{-1}$ (10\% of maximum tolerated dose) 1 day later. Treatment was repeated three times with a 5-day interval. The dose of gemcitabine was titrated to have a minimal effect on the tumour growth to allow investigation of the potential additive or synergistic effects of the combined SWA11 and gemcitabine treatment. Pretreatment with SWA11 mAb lead to substantially retarded tumour growth compared with $\operatorname{IgG}_{2 \mathrm{~A}}$-pretreated control animals or to monotherapy with gemcitabine (Figure 6A). The tumour growth retardation was associated with a decreased percentage of proliferating Ki-67-positive tumour cells (data not shown). We further investigated whether the treatment with gemcitabine would potentiate the effects of SWA11 mAb on tumour cytokine milieu. However, gemcitabine treatment had no effect on the cytokine levels in the tumours (Figure $6 \mathrm{~B}$ and data not shown, compare with Figure 3B).

SWA11 $\mathrm{mAb}$ are less effective in modifying the intratumoural cytokine milieu then anti-L1CAM mAb. We investigated whether changes in intratumoural cytokine milieu are specific for SWA11 mAb treatment. We addressed this issue by treating SKOV3ip tumours with anti-human L1CAM mAb of $\mathrm{IgG}_{2 \mathrm{~A}}$ isotype (Wolterink et al, 2010), which was less effective in inhibiting SKOV3ip tumour growth but had similar effects on tumour cell proliferation (Figure 7A). Intratumoural cytokine profiling revealed that anti-L1CAM $\mathrm{mAb}$ treatment strongly upregulated levels of C5a, CCL3, CXCL10, KC, M-CSF and 


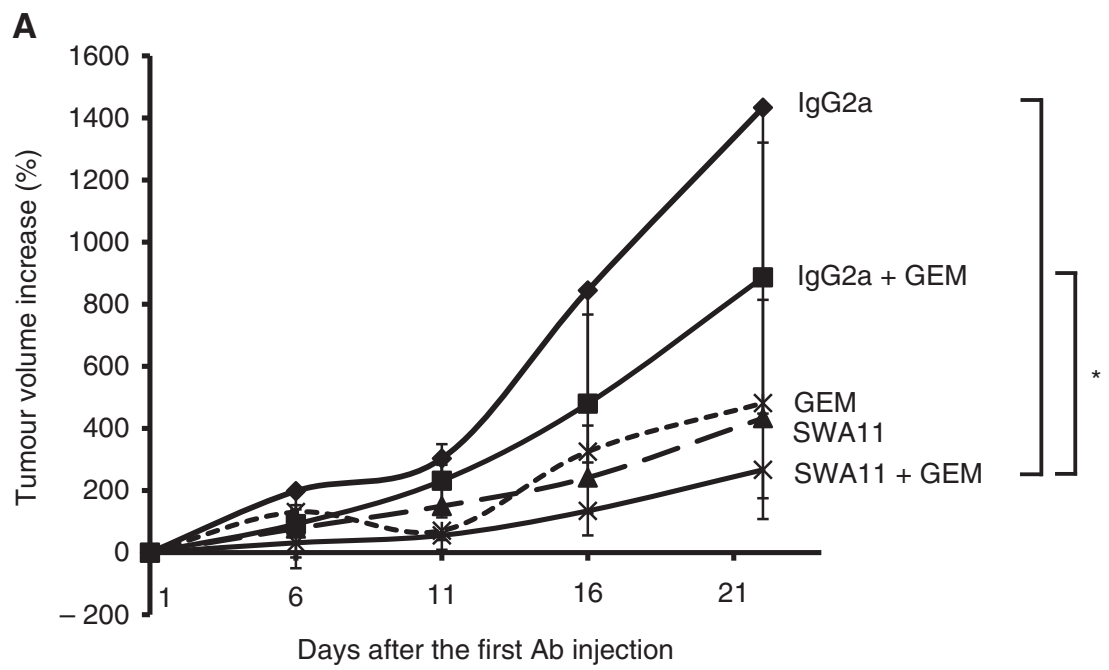

B
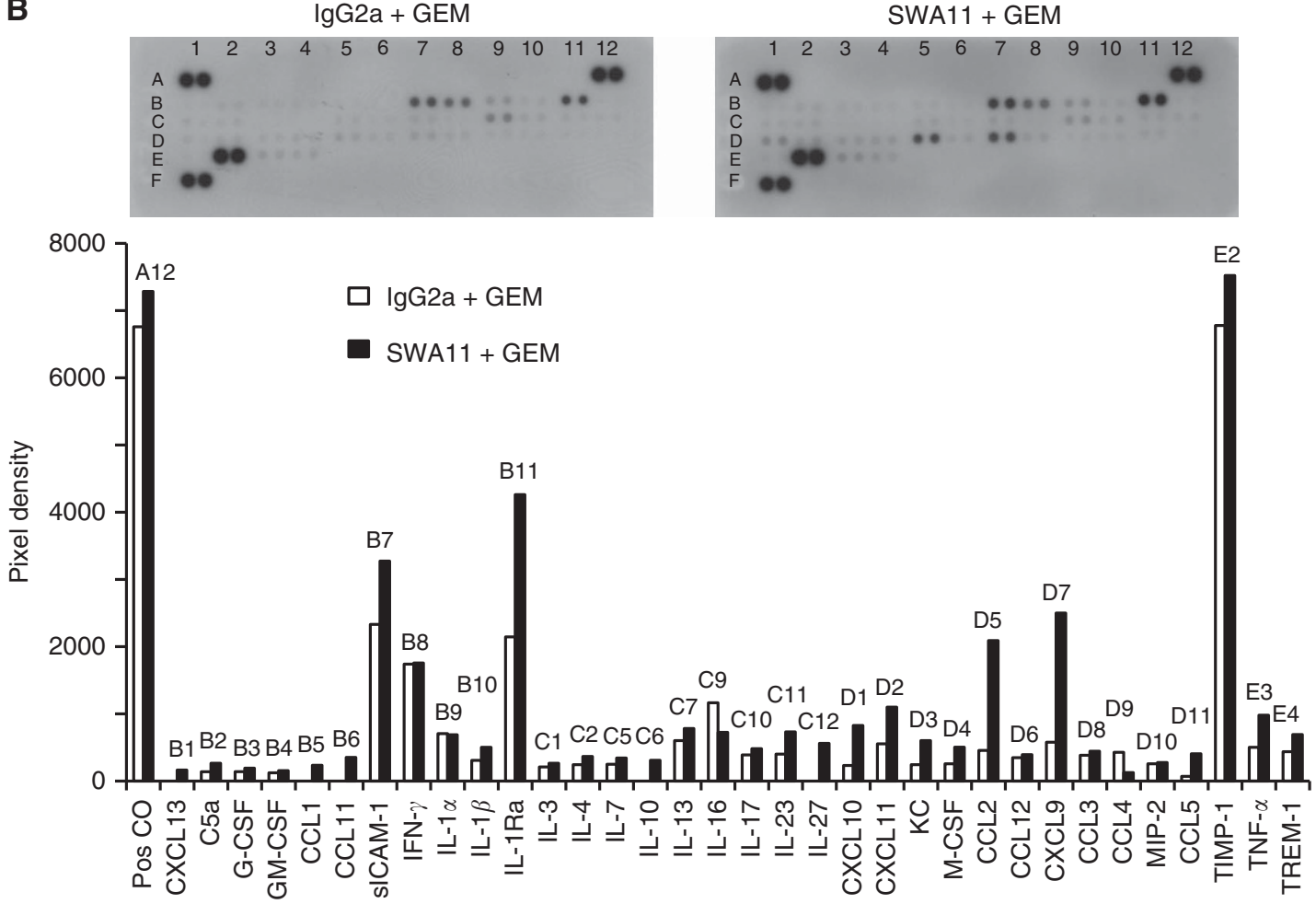

Figure 6. Effects of combined SWA11 mAb and gemcitabine treatment on A549 tumour growth and intratumoural cytokine milieu. (A) SCID beige mice with established xenograft A549 lung carcinomas received treatment with SWA11 mAb (10 mg kg $\left.{ }^{-1}\right)$ or lgG $_{2 A}\left(10 \mathrm{mg} \mathrm{kg}^{-1}\right)$ followed by gemcitabine at a dose of $12 \mathrm{mg} \mathrm{kg}^{-1}$ ( $10 \%$ of maximal tolerated dose) 1 day later ( $n=5$ per group). Control animals received SWA11 mAb $\left(10 \mathrm{mg} \mathrm{kg}^{-1}\right), \operatorname{lgG}_{2 \mathrm{~A}}\left(10 \mathrm{mg} \mathrm{kg}^{-1}\right)$ or gemcitabine $\left(12 \mathrm{mg} \mathrm{kg}^{-1}\right)$ alone $(n=5$ per group). Treatment was repeated three times with a 5 -day interval. External size of A549 tumours was measured with a caliper. ${ }^{*} P<0.05$. Note that part of the results from this experiment are also shown in Figure $1 \mathrm{~A}$ for illustration. (B) Effects of SWA11 mAb and gemcitabine treatment on the levels of 40 different cytokines were determined in A549 tumour lysates using a cytokine protein arrays. The level of cytokines was quantified using ImageJ software.

TNF- $\alpha$ compared with SWA11 mAb (Figure 7B). To investigate potential mechanisms of these differential effects, we analysed expressions of CD24 and L1CAM and their internalisation after antibody binding in A549 and SKOV3ip tumour cells in vitro. SKOV3ip cells expressed both CD24 and L1CAM on the cell surface as analysed by FACS and western blotting (Figures $8 \mathrm{~A}, \mathrm{~B}$ ). In contrast, A549 cells did not express L1CAM (Figures 8A,B). Therefore, only SKOV3ip cells were used for the evaluation of antibody internalisation in the net antibody uptake assay. We found that the SWA11 mAb was internalised much faster than L1-9.3 mAb (Figure 8C,D). Thus, after $90 \mathrm{~min}$ the increase in intracellular fluorescent intensity was $200 \%$ for SWA11 mAb and 50\% for L1-9.3 mAb. The rate of internalisation may contribute to the observed biological effects.

\section{DISCUSSION}

In this study, we show that targeting of CD24 with mAb SWA11 efficiently retarded the growth of lung and ovarian carcinoma xenografts. The effects of SWA11 mAb were mainly attributed to the reduced tumour cell proliferation. Furthermore, we observed a significant reduction in blood vessel density after SWA11 mAb 
A
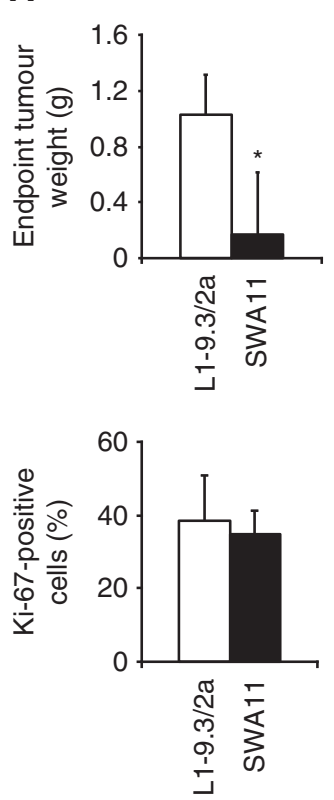

B
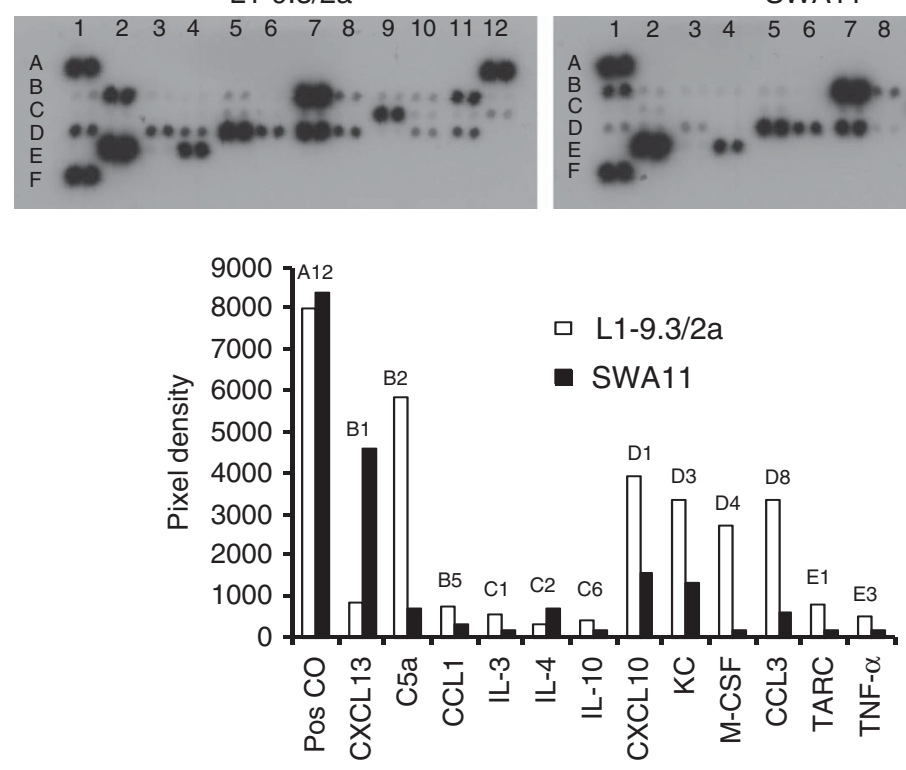

SWA11

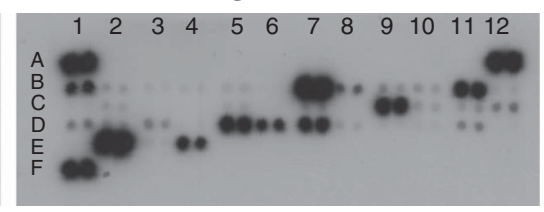

L1-9.3/2a

SWA11

Figure 7. Comparison between the effects of SWA11 mAb and anti-human L1CAM mAb on intratumoural cytokine milieu. (A). Effects of SWA11 and L1CAM mAb on growth and tumour cell proliferation of SKOV3ip tumours. The percentage of Ki-67-positive cells per total tumour cellular mass was determined by immunohistochemistry on frozen tumour sections in $4-5$ tumours per group. ${ }^{*} P<0.05$. (B). CD1 mice inoculated with SKOV3ip ovarian cancer cells received eight doses of either SWA11 mAb $\left(10 \mathrm{mg} \mathrm{kg}^{-1}\right)$ or anti-L1CAM L1-9.3/2a mAb (10 mg kg $\left.{ }^{-1}\right)$ administered two times per week for 4 weeks. Cytokine levels in tumours were determined at the endpoint of treatment using cytokine protein arrays.

therapy, which was probably not due to the vascular maturation or normalisation phenomenon. Importantly, SWA11 mAb treatment strongly influenced intratumoural cytokine milieu and increased infiltration of tumour tissue by macrophages. Effects on the intratumoural cytokine microenvironment were not exclusive for SWA11 mAb treatment because anti-L1CAM mAb also induced changes in the intratumoural cytokine profile, however, different from the SWA11 mAb. Pretreatment of carcinoma xenografts with SWA11 mAb augmented the effects of conventional chemotherapy with gemcitabine. Gemcitabine treatment had no influence on the intratumoural cytokine microenvironment.

Cancer immunotherapy with antibodies or immunotoxins has attracted increased attention following the advancement in technologies for the development of therapeutic antibodies. Because of the established role of CD24 molecule in cancer progression and metastasis (Overdevest et al, 2011) as well as its expression by cancer stem cells in many tumour entities (for a review (Jaggupilli and Elkord, 2012)), CD24 represents a promising novel therapeutic target. Previously, it has been shown that targeting of CD24 reduced tumour cell proliferation in the models of colorectal and pancreatic cancers (Sagiv et al, 2008). A potent anti-tumour activity has also been demonstrated for anti-CD24 immunotoxins based on SWA11 mAb in a Burkitt's lymphoma model (Schnell et al, 1996) and human colorectal cancer models (Shapira et al, 2011). Previously, we have shown that SWA11 mAb treatment decreased the phosphorylation of Src Y416 (active Src) and increased p-Src Y527 (inactive Src) levels in A549 and BxPc-3 tumour models (Bretz et al, 2011; Baumann et al, 2012; Bretz et al, 2012). In the present study we extend these observations by showing that growth retardation of SKOV3ip ovarian and A549 lung tumour models was associated with modulation of intratumoural cytokine milieu after SWA11 mAb treatment. The increased levels of chemoattractants such as CXCL9/MIG and CCL2/MCP-1 in the tumours could also explain the increased infiltration of xenografts by macrophages. Thus, it seems plausible that in addition to the interference with CD24 signalling, SWA11 $\mathrm{mAb}$ exerted its anti-cancer activity via the involvement of ADCC.
We further showed that antibody targeting of another cell surface molecule L1CAM also resulted in increased levels of several cytokines, however, different from those in SWA11 mAb-treated tumours indicating that this phenomenon is not a unique property of SWA11 mAb. Together with the notion that both SWA11 and anti-L1CAM $m A b$ are of $\operatorname{IgG}_{2 \mathrm{~A}}$ isotype these data highlight a role of a target antigen for the modulation of the intratumoural cytokine microenvironment after the therapeutic antibody intervention. In addition, the internalisation rate of tumour antigenbound therapeutic antibodies could be of importance for the Fc-mediated effects and modulation of the cytokine milieu as demonstrated in the present study. Furthermore, our data suggest that interference with CD24 signalling and a modulation of tumour microenvironment by SWA11 sensitised tumour cells to chemotherapy with gemcitabine. Thus, it seems that an addition of anti-CD24 antibody treatment to chemotherapy regimes would be beneficial for targeting of chemotherapyresistant cancer stem cells.

The anti-angiogenic effects of SWA11 mAb treatment could be due to the direct effects of CD24 targeting on the human tumour cells. A similar decrease in the microvessel density after short hairpin RNA targeting of CD24 in SKOV3 cells was observed by Su et al (2009). However, we did not detect a significant reduction in the levels of human proangiogenic factors including VEGF after SWA11 mAb treatment. In contrast, we found a slight upregulation in the levels of some mouse and human proangiogenic factors, which probably represents a compensatory mechanism. In addition, changes in the intratumoural cytokine levels and macrophage infiltration could be responsible for the antiangiogenic effects of SWA11 mAb treatment beside the direct effects on the CD24-positive tumour cells. One possibility is that as a consequence of strong increase in the levels of proinflammatory cytokines the vascular network underwent remodelling or 'normalisation' as was observed in irradiated experimental insulinomas after an increase in CXCL9/MIG and IFN-inducible protein 10 (IP-10) levels (Ganss et al, 2002). Unfortunately, the immunofluorescent analysis of pericyte activation and coverage of tumour 

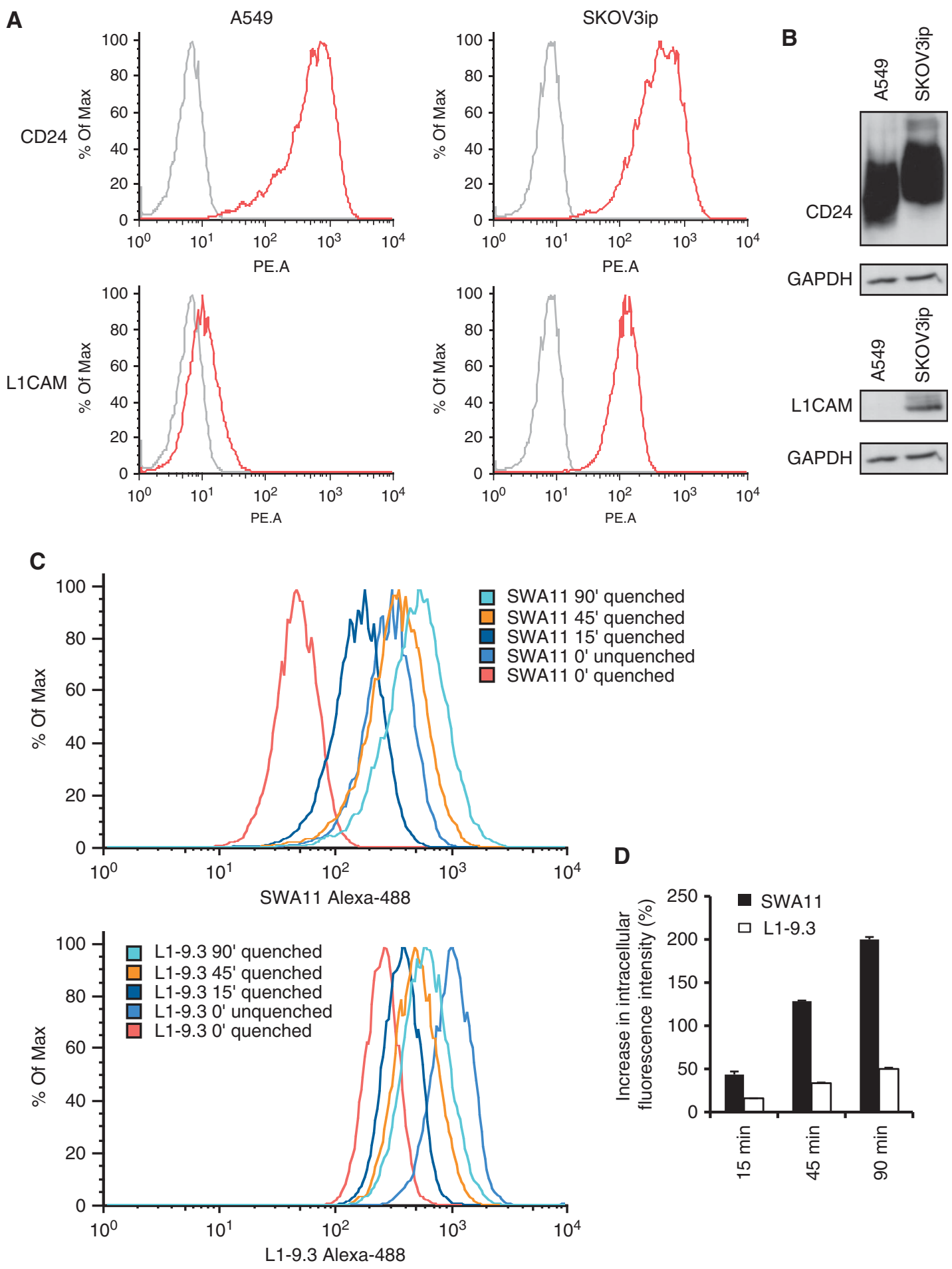

Figure 8. Internalisation rate of SWA11 and L1-9.3 mAb in vitro. (A, B) Expression of CD24 and L1CAM by SKOV3ip and A549 tumour cells was investigated by FACS and western blotting. (C, D) To evaluate the internalisation rate of SWA11 and L1-9.3 mAbs in SKOV3ip cells the net antibody uptake assay was used. Intracellular fluorescence was measured at different time points after quenching the surface-bound Alexa-488labelled mAbs.

microvessels did not provide a strong evidence for the vascular maturation after SWA11 mAb treatment.

One of the limitations of this study is that at the present stage we cannot rule out a potential toxicity of CD24 targeting in cancer patients. The expression of CD24 in normal tissues differs between humans and mice. In particular, in mice CD24 is expressed by erythrocytes in the peripheral blood in addition to blood cell progenitors in the bone marrow. Thus, an application of antimouse CD24 mAb in a mouse syngeneic tumour model of gastric cancer led to a lethal toxicity due to a severe anaemia (data not shown). This systemic toxicity of CD24 targeting by $\mathrm{mAb}$ in a syngeneic tumour model also did not allow the analysis of the changes in the tumour cytokine microenvironment exerted by the anti-CD24 mAb or the extent of ADCC or CDC contribution to the anti-tumour effects of anti-CD24 mAb in immunocompetent mice. However, our data show that SWA11 mAb treatment induced changes in the intratumoural cytokine microenvironment and increased macrophage infiltration even in highly 
immunocompromised NOD SCID or SCID beige mice indicate ADCC involvement in the anti-cancer effects of SWA11 mAb. In addition, a low expression of CD24 in epithelial and muscle tissues and marked overexpression in human tumour tissues makes it an attractive target for the antibody therapy. The potential toxicity of CD24 targeting by Abs could be addressed in human CD24 transgenic mice; however, this was not feasible in the present study because these mice are not yet developed.

In conclusion, our data demonstrate that CD24 targeting by $\mathrm{mAb}$ could be beneficial in anti-cancer treatment regimens including its combination with conventional chemotherapy.

\section{ACKNOWLEDGEMENTS}

This work was supported by grants from the DKFZ-BSP Alliance and Deutsche Krebshilfe (109745) to GM, TS and PA. We thank Elvira Hallauer and Jury Gladkich for excellent technical assistance.

\section{REFERENCES}

Ahmed MA, Al-Attar A, Kim J, Watson NF, Scholefield JH, Durrant LG, Ilyas M (2009) CD24 shows early upregulation and nuclear expression but is not a prognostic marker in colorectal cancer. J Clin Pathol 62: 1117-1122.

Aigner S, Ramos CL, Hafezi-Moghadam A, Lawrence MB, Friederichs J, Altevogt P, Ley K (1998) CD24 mediates rolling of breast carcinoma cells on P-selectin. FASEB J 12: 1241-1251.

Aigner S, Sthoeger ZM, Fogel M, Weber E, Zarn J, Ruppert M, Zeller Y, Vestweber D, Stahel R, Sammar M, Altevogt P (1997) CD24, a mucin-type glycoprotein, is a ligand for P-selectin on human tumor cells. Blood 89: 3385-3395.

Baumann P, Cremers N, Kroese F, Orend G, Chiquet-Ehrismann R, Uede T, Yagita H, Sleeman JP (2005) CD24 expression causes the acquisition of multiple cellular properties associated with tumor growth and metastasis. Cancer Res 65: 10783-10793.

Baumann P, Thiele W, Cremers N, Muppala S, Krachulec J, Diefenbacher M, Kassel O, Mudduluru G, Allgayer H, Frame M, Sleeman JP (2012) CD24 interacts with and promotes the activity of c-src within lipid rafts in breast cancer cells, thereby increasing integrin-dependent adhesion. Cell Mol Life Sci 69: 435-448.

Bretz N, Noske A, Keller S, Erbe-Hofmann N, Schlange T, Salnikov A, Moldenhauer G, Kristiansen G, Altevogt P (2011) CD24 promotes tumorcell invasion by suppressing tissue factor pathway inhibitor-2 (TFPI-2) in a c-Src-dependent fashion. Clin Exp Metastasis 29: 27-38.

Bretz NP, Salnikov AV, Perne C, Keller S, Wang X, Mierke CT, Fogel M, Erbe-Hofmann N, Schlange T, Moldenhauer G, Altevogt P (2012) CD24 controls Src/STAT3 activity in human tumors. Cell Mol Life Sci 69(22): 3863-3879.

Fang X, Zheng P, Tang J, Liu Y (2010) CD24: from A to Z. Cell Mol Immunol 7: $100-103$

Friederichs J, Zeller Y, Hafezi-Moghadam A, Grone HJ, Ley K, Altevogt P (2000) The CD24/P-selectin binding pathway initiates lung arrest of human A125 adenocarcinoma cells. Cancer Res 60: 6714-6722.

Fukushima T, Tezuka T, Shimomura T, Nakano S, Kataoka H (2007) Silencing of insulin-like growth factor-binding protein-2 in human glioblastoma cells reduces both invasiveness and expression of progression-associated gene CD24. J Biol Chem 282: 18634-18644.

Galluzzi L, Vacchelli E, Fridman WH, Galon J, Sautes-Fridman C, Tartour E, Zucman-Rossi J, Zitvogel L, Kroemer G (2012) Trial watch: monoclonal antibodies in cancer therapy. Oncoimmunology 1: 28-37.

Ganss R, Ryschich E, Klar E, Arnold B, Hammerling GJ (2002) Combination of T-cell therapy and trigger of inflammation induces remodeling of the vasculature and tumor eradication. Cancer Res 62: 1462-1470.

Jackson D, Waibel R, Weber E, Bell J, Stahel RA (1992) CD24, a signaltransducing molecule expressed on human B cells, is a major surface antigen on small cell lung carcinomas. Cancer Res 52: 5264-5270.

Jaggupilli A, Elkord E (2012) Significance of CD44 and CD24 as cancer stem cell markers: an enduring ambiguity. Clin Dev Immunol 2012: 708036.
Kay R, Rosten PM, Humphries RK (1991) CD24, a signal transducer modulating B cell activation responses, is a very short peptide with a glycosyl phosphatidylinositol membrane anchor. J Immunol 147: 1412-1416.

Kristiansen G, Machado E, Bretz N, Rupp C, Winzer KJ, Konig AK, Moldenhauer G, Marme F, Costa J, Altevogt P (2010) Molecular and clinical dissection of CD24 antibody specificity by a comprehensive comparative analysis. Lab Invest 90: 1102-1116.

Kristiansen G, Sammar M, Altevogt P (2004) Tumour biological aspects of CD24, a mucin-like adhesion molecule. J Mol Histol 35: 255-262.

Mierke CT, Bretz N, Altevogt P (2011) Contractile forces contribute to increased GPI-anchored receptor CD24 facilitated cancer cell invasion. J Biol Chem 286: 34858-34871.

Overdevest JB, Thomas S, Kristiansen G, Hansel DE, Smith SC, Theodorescu D (2011) CD24 offers a therapeutic target for control of bladder cancer metastasis based on a requirement for lung colonization. Cancer Res 71: 3802-3811.

Presta LG (2008) Molecular engineering and design of therapeutic antibodies. Curr Opin Immunol 20: 460-470.

Reichert JM (2011) Antibody-based therapeutics to watch in 2011. MAbs 3: 76-99.

Reichert JM (2012) Marketed therapeutic antibodies compendium. MAbs 4: $413-415$.

Runz S, Mierke CT, Joumaa S, Behrens J, Fabry B, Altevogt P (2008) CD24 induces localization of beta1 integrin to lipid raft domains. Biochem Biophys Res Commun 365: 35-41.

Sagiv E, Starr A, Rozovski U, Khosravi R, Altevogt P, Wang T, Arber N (2008) Targeting CD24 for treatment of colorectal and pancreatic cancer by monoclonal antibodies or small interfering RNA. Cancer Res 68: 2803-2812.

Schabath H, Runz S, Joumaa S, Altevogt P (2006) CD24 affects CXCR4 function in pre-B lymphocytes and breast carcinoma cells. J Cell Sci 119: 314-325.

Schnell R, Katouzi AA, Linnartz C, Schoen G, Drillich S, Hansmann ML, Schiefer D, Barth S, Zangemeister-Wittke U, Stahel RA, Diehl V, Engert A (1996) Potent anti-tumor effects of an anti-CD24 ricin A-chain immunotoxin in vitro and in a disseminated human Burkitt's lymphoma model in SCID mice. Int J Cancer 66: 526-531.

Scott AM, Wolchok JD, Old LJ (2012) Antibody therapy of cancer. Nat Rev Cancer 12: 278-287.

Senner V, Sturm A, Baur I, Schrell UH, Distel L, Paulus W (1999) CD24 promotes invasion of glioma cells in vivo. J Neuropathol Exp Neurol 58: 795-802.

Shapira S, Shapira A, Starr A, Kazanov D, Kraus S, Benhar I, Arber N (2011) An immunoconjugate of anti-CD24 and Pseudomonas exotoxin selectively kills human colorectal tumors in mice. Gastroenterology 140: 935-946.

Shuptrine CW, Surana R, Weiner LM (2012) Monoclonal antibodies for the treatment of cancer. Semin Cancer Biol 22: 3-13.

Smith SC, Oxford G, Wu Z, Nitz MD, Conaway M, Frierson HF, Hampton G, Theodorescu D (2006) The metastasis-associated gene CD24 is regulated by Ral GTPase and is a mediator of cell proliferation and survival in human cancer. Cancer Res 66: 1917-1922.

Su D, Deng H, Zhao X, Zhang X, Chen L, Chen X, Li Z, Bai Y, Wang Y, Zhong Q, Yi T, Qian Z, Wei Y (2009) Targeting CD24 for treatment of ovarian cancer by short hairpin RNA. Cytotherapy 11: 642-652.

Vanneman M, Dranoff G (2012) Combining immunotherapy and targeted therapies in cancer treatment. Nat Rev Cancer 12: 237-251.

Wang W, Wang X, Peng L, Deng Q, Liang Y, Qing H, Jiang B (2010) CD24dependent MAPK pathway activation is required for colorectal cancer cell proliferation. Cancer Sci 101: 112-119.

Wolterink S, Moldenhauer G, Fogel M, Kiefel H, Pfeifer M, Luttgau S, Gouveia R, Costa J, Endell J, Moebius U, Altevogt P (2010) Therapeutic antibodies to human L1CAM: functional characterization and application in a mouse model for ovarian carcinoma. Cancer Res 70: 2504-2515.

Woodward WA, Sulman EP (2008) Cancer stem cells: markers or biomarkers? Cancer Metastasis Rev 27: 459-470.

This work is published under the standard license to publish agreement. After 12 months the work will become freely available and the license terms will switch to a Creative Commons AttributionNonCommercial-Share Alike 3.0 Unported License.

Supplementary Information accompanies this paper on British Journal of Cancer website (http://www.nature.com/bjc) 